\title{
Out-of-hospital emergency care providers' work and clinical skills in Finland: A follow-up study
}

\author{
Riitta Mikkola*1, Mari Salminen-Tuomaala², Eija Paavilainen ${ }^{1}$, Päivi Leikkola ${ }^{3}$ \\ ${ }^{1}$ School of Health Sciences, University of Tampere, Tampere, Finland \\ ${ }^{2}$ School of Health Care and Social Work, University of Applied Sciences, Seinäjoki, Finland \\ ${ }^{3}$ Hospital District of South Ostrobothnia, Seinäjoki, Finland
}

Received: October 18, 2017

DOI: $10.5430 /$ cns.v6n1p51
Accepted: November 7, $2017 \quad$ Online Published: November 13, 2017

URL: https://doi.org/10.5430/cns.v6n1p51

\begin{abstract}
Objective: This follow-up study is part of a larger study on emergency medical services. Its purpose was to describe emergency care providers' perceptions of their work, its challenges and their clinical competence. The study aimed at producing knowledge of the perceived influence of an educational intervention, to be used in developing emergency care providers' further and updating education.

Methods: Data were collected from staff working in out-of-hospital emergency care of a hospital district in Finland using a questionnaire developed for this purpose. The results were analyzed statistically using SPSS for Windows 24.

Results: Over $90 \%$ of the respondents found that their work was interesting and provided sufficient challenges. The majority were also interested in continuous professional development. After the educational intervention, respondents found the work somewhat more challenging and slightly more strenuous both physically and mentally compared to the first survey. Respondents more commonly reported that new capacities were required at work and they rated their practical skills lower than in the first survey. However, work in a multiprofessional environment was found less challenging. Over $70 \%$ of the respondents planned to have further education in the near future. They rated their clinical skills as good, but slightly lower compared to the first survey. Conclusions: The results regarding work, its challenges and self-rated clinical competence remained the same or were somewhat poorer after the educational intervention. The results help improve the education to meet the needs of emergency staff.
\end{abstract}

Key Words: Prehospital, Paramedic care, Emergency care workers, Clinical skills

\section{INTRODUCTION}

Emergency care providers' work has undergone many changes over the past decades. ${ }^{[1-4]}$ There has been a shift in emergency medical services towards providing care on emergency scenes, which means that the patient is not necessarily transported to hospital. ${ }^{[5]}$ It also means that a wider range of skills and competence is now required from emergency care providers. $^{[2]}$ Their role description has been expanded to include the treatment of minor acute conditions, for example wounds, minor burns, ${ }^{[5]}$ hypoglycemia, ${ }^{[6]}$ epistaxis ${ }^{[7]}$ and falls. ${ }^{[8]}$ The changed role description and care of patients on scene instead of conveyance to hospital also bring into focus the importance of teamwork with other professionals. Emergency care providers collaborate with various authorities, hospital staff and other professional groups. ${ }^{[9]}$ Besides caring for patients, encountering and attending to family members is an essential part of emergency care providers' work in non-conveyance situations. A special challenge is

\footnotetext{
*Correspondence: Riitta Mikkola; Email: riittakmikkola@gmail.com; Address: School of Health Sciences, University of Tampere, Tampere,
} Finland. 
posed by the need to ensure appropriate follow-up care and counseling. ${ }^{[10]}$

A high level of theoretical and practical competence is required from professionals working in emergency care. They are expected to promptly assess the patient status, make decisions and initiate intensive level treatment on scene. ${ }^{[4,11]}$ Their work is more independent than earlier and entails an increasing amount of responsibility. Considering the responsibility of treating life-threatening conditions in accordance with patient safety requirements in sometimes challenging settings, it has been suggested that staff competence and skills should be evaluated and suitable continuing education programs offered regularly. ${ }^{[12]}$

The concept clinical skill has been seen to refer to a set of fundamental skills required by those working in emergency care settings, such as the use of hemodynamic support devices. ${ }^{[13]}$ In the narrowest sense, clinical skills or competence can refer to professional activities performed to help patients, based on the professional's knowledge, skills and judgment associated with the specialty. In a wider sense, the professional's scope of practice includes skills such as gathering data, solving problems and delivering information, besides performing procedures and treatments. ${ }^{[14]}$

Clinical skills require repetition to become established. Skills applied infrequently are experienced as a challenge in emergency care; continual training and practicing is required to develop these skills. It was reported in a study that seven skills had been used by all of the paramedic respondents in the previous week and that the respondents felt high confidence with these skills (primary survey, vital signs measurement, chest auscultation, pulse oximetry, neurological assessment, cardiac rhythm interpretation, and drug administration). Despite this, over half of the paramedics in the study said that simulation should be used to practice five of the skills at least twice annually. ${ }^{[15]}$ Joint education programs for various professional groups have also been found important to promote collaborative practice. ${ }^{[16]}$ Successful teamwork facilitates the optimal use of each worker's skills and it can, among other things, help prevent medication errors. ${ }^{[17]}$ Multi-professional continuing education based on simulation pedagogy has been found an especially useful method of practicing teamwork and clinical skills required to manage the rapidly changing situations in emergency care. ${ }^{[18]}$

\section{Aim}

The purpose of the study was to describe how nurses, practical nurses, emergency medical technicians (EMT) and hospital and ambulance attendants working in out-of-hospital emergency care services experience their work, its challenges and their clinical competence after having completed an educational intervention. The study aimed at producing new knowledge that can be used to develop further and updating education for out-of-hospital emergency care staff.

The research questions focused on the following aspects in particular:

- How do out-of-hospital emergency care providers experience their work and its challenges after having completed an educational intervention?

- How do out-of-hospital emergency care providers rate their clinical competence after having completed an educational intervention?

\section{MeThODS}

\subsection{Study design}

The survey reported on here, conducted with emergency staff in a hospital district in Finland, is part of a longitudinal study which consist of several phases: development and pre-testing of a questionnaire, the first survey, an educational intervention and the second survey. The educational intervention addressed patients' experiences of out-of-hospital emergency care, the development of current practices in the care of acutely ill patients, the management of major and multiple patient incidents and similar topics.

\subsection{Data collection and instrument}

Data for this research were collected in the region of one hospital district in Finland using the Webropol online survey software. No amendments had been made to the questionnaire after the pilot study $(\mathrm{N}=17)$, so these results were included in the main results. The first data collection took place in September-October $2014(\mathrm{~N}=142)$ and the second in October-November $2016(\mathrm{~N}=86)$. The educational intervention was delivered to the entire emergency staff in November 2015.

The questionnaire used had been developed for this research specifically. It was based on literature and earlier research. ${ }^{[1,3,19]}$ The questionnaire started with 8 background questions about respondents' sex, age, qualification, current position and type of employment and about their work experience in the current occupation, in emergency medical care and in the health service in general. Respondents' experiences of the work and its challenges were examined using 7-point Likert scale statements $(1=$ not part of my role, $2=$ totally disagree, $3=$ disagree, $4=$ somewhat disagree, $5=$ somewhat agree, $6=$ agree, $7=$ totally agree). The response "not part of my role" was classified as missing information in the analysis. The statement "I am unsure about carrying out new or infrequent procedures" was complemented 
with a request to specify the procedures that caused uncertainty. Respondents' clinical skills were examined using a 10-point Likert scale, on which 1 represented completely lacking skills and 10 excellent skills.

\subsection{Data analysis}

Both sets of data were analyzed using SPSS for windows (study I version 22, study II version 24, Armonk, NY: IBM Corp.). The data were summarized in the printout using straight distributions, medians, means and cross tabulations, and the distribution of variables and their mutual dependence were examined. Statistical significance was described by the $p$-value, set at $p<.050$. Lower values were regarded as indicative of a dependence or difference. ${ }^{[20]}$

Respondents were classified into four groups according to age ( $<25,25-34,35-44$ and $>45$ years) and into two groups according to their position in basic or advanced level emergency care. They were also classified according to their qualification to nurses and other qualifications, which included practical nurses, EMT and hospital and ambulance attendants. The categories for work experience in current position were $<1.5,1.5-2.4$ and 2.5 or more years in the first survey, and $\leq 2,2.1-3.9$ and 4 or more years in the second survey. In regard to work, the categorization was $<3,3-8$ and 8 or more years in the first, and $<4,4-10$ and $>10$ years in the second survey. The categorization was changed to ensure that each category had an adequate number of observations for analysis.

Responses to the statements on emergency care providers' work and its challenges were first classified into four categories in the final printout $(1=$ disagree or totally disagree, 2 = somewhat disagree, $3=$ somewhat agree, $4=$ agree or totally agree). In regard to clinical skills, the responses were classified into five categories $(1=$ completely or almost lacking skills, 2 = quite lacking skills, 3 = average skills, $4=$ good skills and $5=$ excellent skills).

In this report, the focus is on the follow-up study and on the developments observed since the first survey. The results of the first survey have been published in greater detail in earlier articles. ${ }^{[9,12]}$

\subsection{Ethical considerations}

All participants were voluntary and they had been informed of the various phases of the study. In the report, the results have been anonymized so that respondents cannot be identified. ${ }^{[21]}$ During the research process, participants had an opportunity to communicate with the investigators. The relevant research approval and assent of Pirkanmaa Hospital District Ethics Committee (R13164H) to conduct the study were obtained.

Published by Sciedu Press

\section{Results}

\subsection{Participants}

As shown in Table 1, the first phase of the research involved 142 and the second 86 emergency care providers. There was an equal number of women and men in the first survey, whereas in the second survey, the rates were approximately $62 \%$ female and $38 \%$ male. The share of under 25 -year-olds was nearly $20 \%$ in the first phase, but under $10 \%$ in the second phase. Approximately $65 \%$ of the respondents in both surveys worked in basic level emergency care. The majority of them were nurses (study I circa 61\%, study II circa 70\%). Almost $80 \%$ of all participants had a permanent position. The mean length of work experience was approximately 8 years in emergency care and 10 years in the health service.

\subsection{Emergency care providers' perception of their work and its challenges}

Table 2 shows that compared to the first survey, there was little change in respondents' perception of their work and its challenges after the educational intervention. The results were partly poorer in the latter survey; respondents in the second survey found their work mentally somewhat more taxing and their theoretical and practical skills, capability for independent work and skills in multiple patient or disaster situations somewhat poorer. In addition, compared to the first survey, after the educational intervention a clearly larger share of respondents planned to obtain further education in the near future and also found working in a multi-professional work environment less challenging.

\subsubsection{Emergency care providers' experience of their work} Respondents in both surveys $(96.5 \%$ in the first study and $93.0 \%$ in the follow-up study) regarded their work in emergency medical services as interesting. In both surveys, $90.0 \%$ of the respondents agreed that their work involved sufficient challenges. Slightly under $20.0 \%$ felt that the work was dominated by constant rush.

In the first survey, $36.0 \%$ of the respondents reported that their work was physically strenuous. After the educational intervention, the share of those agreeing with the statement had grown to $41.0 \%$. Secondly, $30.0 \%$ of the emergency care providers found their work mentally taxing in the first survey. In the follow-up study, this rate had grown to $46.5 \%$. The permanent staff found the work mentally taxing more commonly than temporary workers (permanent staff $51.0 \%$, staff on contract $32.0 \%, p=.011$ ). In those who had worked less than 3 years in emergence services, $23.0 \%$ agreed that the work was mentally taxing, whereas in workers with over 8 years of experience, the rate was $63.0 \%(p=.032)$. Similarly, a longer experience in the health service correlated with the experience of mentally taxing work; Over half of the respon- 
dents $(54.5 \%)$ with more than 10 years' work experience in the health service agreed with this statement, while the share

Table 1. Demographic data on the participants

\begin{tabular}{|c|c|c|c|c|}
\hline \multirow{2}{*}{ Participants } & \multicolumn{2}{|c|}{ Survey I } & \multicolumn{2}{|c|}{ Survey II } \\
\hline & $\mathbf{N}$ & $\%$ & $\mathbf{N}$ & $\%$ \\
\hline \multicolumn{5}{|l|}{$\operatorname{Sex}(n=142, n=86)$} \\
\hline - Women & 71 & 50 & 53 & 61.6 \\
\hline - Men & 71 & 50 & 33 & 38.4 \\
\hline \multicolumn{5}{|l|}{ Age $(n=142, n=86)$} \\
\hline - Under 25 years old & 23 & 16.2 & 8 & 9.3 \\
\hline - 25-34 years old & 55 & 38.7 & 47 & 54.7 \\
\hline - 35-44 years old & 40 & 28.2 & 16 & 18.6 \\
\hline - Over 45 years old & 24 & 16.9 & 15 & 17.4 \\
\hline \multicolumn{5}{|l|}{ Current job level $(n=142, n=86)$} \\
\hline - Basic level emergency care & 93 & 65.5 & 55 & 64 \\
\hline - Advanced level emergency care & 49 & 34.5 & 31 & 36 \\
\hline \multicolumn{5}{|l|}{ Occupation $(\mathrm{n}=142, \mathrm{n}=86)$} \\
\hline - Hospital and ambulance attendant & 56 & 39.4 & 26 & 30.2 \\
\hline \multicolumn{5}{|l|}{$\mathrm{EMT}^{*} /$ practical nurse } \\
\hline - Nurse & 86 & 60.6 & 60 & 69.8 \\
\hline \multicolumn{5}{|l|}{ Employment $(\mathrm{n}=142, \mathrm{n}=86)$} \\
\hline - Permanent & 106 & 74.6 & 67 & 77.9 \\
\hline - On contract & 36 & 25.4 & 19 & 22.1 \\
\hline \multicolumn{5}{|c|}{ Work experience in current position $(n=141, n=86)$} \\
\hline - Less than 1.5 years/2 years or less ${ }^{* *}$ & 33 & 23.4 & 24 & 27.9 \\
\hline - 1.5 years-2.4 years/2.1 years-3.9 years ${ }^{* *}$ & 76 & 53.9 & 43 & 50 \\
\hline - 2.5 years or more/4 years or more ${ }^{* *}$ & 32 & 22.7 & 19 & 22.1 \\
\hline \multicolumn{5}{|c|}{ Working experience in health services $(n=140, n=86)$} \\
\hline - Less than 3 years/4 years or less ${ }^{* *}$ & 25 & 17.8 & 20 & 23.3 \\
\hline - 3-8 years/over 4 years-10 years ${ }^{* *}$ & 55 & 39.3 & 33 & 38.4 \\
\hline - 8 years or more/over 10 years ${ }^{* *}$ & 60 & 42.9 & 33 & 38.4 \\
\hline
\end{tabular}

Note. ${ }^{*}$ EMT=emergency medical technician; ${ }^{* * *}$ Survey II

\subsubsection{Self-rated competence in emergency care}

Respondents rated their capability for independent work lower in the follow-up study. In the first survey, $82 \%$ and in the follow-up study, $71 \%$ of the respondents found that they possessed sufficient capability for independent work. Similarly, the survey conducted before the educational intervention showed that $92 \%$ of the care providers thought that they were capable of quickly assessing patients' urgent care needs, whereas the rate was $80 \%$ in the second survey. The majority (over 90\%) of the respondents in both surveys agreed that they were able to work under pressure. Half of the care providers in the first survey reported that they had received sufficient orientation for their duties. After the intervention, the result was $43 \%$. In this second survey, $30 \%$ of the nurses and $73 \%$ of the other professionals $(p=.001)$ said that the orientation had been sufficient. In regard to the challenge of implementing care quickly in changing circumstances, respondents rated their capability slightly lower 54 was $25.0 \%$ in those who had worked 4 years or less in the health service $(p=.015)$. 
Table 2. Emergency care providers' perception of their work and its challenges

\begin{tabular}{|c|c|c|c|c|c|c|}
\hline \multirow[t]{2}{*}{ Emergency care providers' work } & \multicolumn{2}{|c|}{$\begin{array}{l}\text { Survey } \\
\text { (Mean) }\end{array}$} & \multicolumn{2}{|c|}{$\begin{array}{c}\text { Survey } \\
\text { (Median) }\end{array}$} & \multicolumn{2}{|c|}{$\begin{array}{l}\text { Survey } \\
\text { (Range) }\end{array}$} \\
\hline & $\mathbf{I}$ & II & $\mathbf{I}$ & II & $\mathbf{I}$ & II \\
\hline \multicolumn{7}{|l|}{ Experience of work } \\
\hline - My work is interesting $(\mathrm{N}=142, \mathrm{~N}=86)$ & 3.92 & 3.92 & 4.00 & 4.00 & $1-4$ & $2-4$ \\
\hline - There are sufficient challenges at work $(\mathrm{N}=142, \mathrm{~N}=86)$ & 3.89 & 3.88 & 4.00 & 4.00 & $2-4$ & $2-4$ \\
\hline - The work is dominated by constant rush $(\mathrm{N}=142, \mathrm{~N}=86)$ & 2.54 & 2.51 & 3.00 & 3.00 & $1-4$ & $1-4$ \\
\hline - My work is physically strenuous $(\mathrm{N}=142, \mathrm{~N}=86)$ & 3.05 & 3.08 & 3.00 & 3.00 & $1-4$ & $1-4$ \\
\hline - The work is mentally taxing $(\mathrm{N}=142, \mathrm{~N}=86)$ & 2.96 & 3.26 & 3.00 & 3.00 & $1-4$ & $1-4$ \\
\hline \multicolumn{7}{|l|}{ Self-rated competence } \\
\hline - I possess sufficient capability for independent work $(\mathrm{N}=142, \mathrm{~N}=86)$ & 3.80 & 3.71 & 4.00 & 4.00 & $1-4$ & $3-4$ \\
\hline - I can quickly assess the patients' urgent care needs $(\mathrm{N}=142, \mathrm{~N}=86)$ & 3.92 & 3.79 & 4.00 & 4.00 & $3-4$ & $2-4$ \\
\hline - I can work under pressure $(\mathrm{N}=142, \mathrm{~N}=86)$ & 3.95 & 3.91 & 4.00 & 4.00 & $3-4$ & $3-4$ \\
\hline - I have received sufficient orientation for my duties $(\mathrm{N}=142, \mathrm{~N}=86)$ & 3.24 & 3.09 & 4.00 & 4.00 & $1-4$ & $1-4$ \\
\hline $\begin{array}{l}\text { - I have sufficient capability to implement care quickly in changing circumstances } \\
(\mathrm{N}=142, \mathrm{~N}=86)\end{array}$ & 3.83 & 3.65 & 4.00 & 4.00 & $2-4$ & $2-4$ \\
\hline - My ability to make independent decisions is sufficient $(\mathrm{N}=142, \mathrm{~N}=86)$ & 3.79 & 3.60 & 4.00 & 4.00 & $1-4$ & $2-4$ \\
\hline $\begin{array}{l}\text { - New capacities are continuously required as work practices change } \\
(\mathrm{N}=142, \mathrm{~N}=86)\end{array}$ & 3.44 & 3.62 & 4.00 & 4.00 & $1-4$ & $2-4$ \\
\hline $\begin{array}{l}\text { - My theoretical knowledge and skills are sufficient for performing my duties } \\
(\mathrm{N}=142, \mathrm{~N}=86)\end{array}$ & 3.80 & 3.56 & 4.00 & 4.00 & $2-4$ & $2-4$ \\
\hline \multicolumn{7}{|l|}{ Practical skills } \\
\hline - I have good technical skills for performing the procedures $(\mathrm{N}=142, \mathrm{~N}=86)$ & 3.63 & 3.37 & 4.00 & 4.00 & $1-4$ & $1-4$ \\
\hline - I have good skills in the use of equipment and instruments $(\mathrm{N}=142, \mathrm{~N}=86)$ & 3.82 & 3.70 & 4.00 & 4.00 & $2-4$ & $2-4$ \\
\hline - I have sufficient practical skills $(\mathrm{N}=142, \mathrm{~N}=86)$ & 3.87 & 3.71 & 4.00 & 4.00 & $2-4$ & $2-4$ \\
\hline $\begin{array}{l}\text { - I have sufficient skills to operate in multiple patient or disaster situations } \\
(\mathrm{N}=142, \mathrm{~N}=86)\end{array}$ & 3.05 & 2.76 & 3.00 & 3.00 & $1-4$ & $1-4$ \\
\hline - I am unsure about carrying out new or infrequent procedures $(\mathrm{N}=142, \mathrm{~N}=86)$ & 2.65 & 2.97 & 3.00 & 3.00 & $1-4$ & $1-4$ \\
\hline \multicolumn{7}{|l|}{ Self-development } \\
\hline - I want to develop my professional competence continuously $(\mathrm{N}=142, \mathrm{~N}=86)$ & 3.90 & 3.85 & 4.00 & 4.00 & $1-4$ & $1-4$ \\
\hline $\begin{array}{l}\text { My training gives me the competence required for my current job } \\
(\mathrm{N}=142, \mathrm{~N}=86)\end{array}$ & 3.64 & 3.41 & 4.00 & 4.00 & $1-4$ & $1-4$ \\
\hline - I plan to obtain further training $(\mathrm{N}=142, \mathrm{~N}=86)$ & 3.39 & 3.57 & 4.00 & 4.00 & $1-4$ & $1-4$ \\
\hline \multicolumn{7}{|l|}{ Support and cooperation } \\
\hline - I receive sufficient support from my colleagues $(\mathrm{N}=142, \mathrm{~N}=86)$ & 3.59 & 3.52 & 4.00 & 4.00 & $1-4$ & $1-4$ \\
\hline $\begin{array}{l}\text { - I receive sufficient help and advice from the emergency doctor on duty } \\
(\mathrm{N}=142, \mathrm{~N}=86)\end{array}$ & 2.96 & 3.31 & 3.00 & 4.00 & $1-4$ & $1-4$ \\
\hline - I receive sufficient support from my superior/employer $(\mathrm{N}=142, \mathrm{~N}=85)$ & 2.71 & 2.41 & 3.00 & 3.00 & $1-4$ & $1-4$ \\
\hline $\begin{array}{l}\text { - It is challenging to work in a multiprofessional environment } \\
(\mathrm{N}=142, \mathrm{~N}=86)\end{array}$ & 2.87 & 2.62 & 3.00 & 3.00 & $1-4$ & $1-4$ \\
\hline - Cooperation with the regional hospitals is smooth $(\mathrm{N}=142, \mathrm{~N}=85)$ & 3.13 & 3.11 & 3.00 & 3.00 & $1-4$ & $1-4$ \\
\hline - Cooperation with the dispatch center is smooth $(\mathrm{N}=142, \mathrm{~N}=86)$ & 3.13 & 3.86 & 3.00 & 4.00 & $1-4$ & $3-4$ \\
\hline
\end{tabular}

Note. 1 = disagree or fully disagree, 2 = somewhat disagree, $3=$ somewhat agree, $4=$ agree or fully agree

\subsubsection{Practical skills}

The majority of the respondents found that their practical skills were sufficient for the work in emergency care. In the first survey, the rate was $90 \%$ of the respondents. In the follow-up study, $73 \%$ of the care providers found their practical skills sufficient. It was also discovered that $81 \%$ of the respondents with over 8 years' experience in emergency care felt confident about their practical skills, whereas just half of those with under 3 years of experience felt the same way $(p=.025)$. In the first survey, $36 \%$ of the respondents reported that they had sufficient skills to operate in a multiple patient or disaster situation, but in the follow-up study only $22 \%$ agreed or fully agreed with this statement. The share of respondents who felt confident about having good technical skills for performing various procedures also decreased from $64 \%$ in the first survey to $51 \%$ in the second survey. Before the intervention, $85 \%$ of the respondents found that they had good skills in the use of equipment and instruments, whereas the follow-up study yielded the result $71 \%$. Almost one fourth $(23 \%)$ of the respondents in the first survey and one third of the respondents in the second survey admitted feeling unsure about carrying out new or infrequent procedures. The 
feeling of insecurity was slightly more common in women $(36 \%)$ than men $(27 \%, p=.003)$ in the follow-up study. Insecurity was most commonly associated with intraosseous infusion, needle thoracostomy, cardiac synchronization, pediatric patients, multiple patient or disaster situations and childbirth.

\subsubsection{Self-development}

In the first survey, $75 \%$ of the respondents found that their education had provided them with the competence required for their current work. In the follow-up study, 59\% of the care providers agreed or agreed fully with this statement. The majority of respondents (approximately 90\%) in both surveys were interested in continuously developing their professional competence. In the follow-up study, all of the under 25-year-old respondents wanted to develop their competence, whereas in the group 45 or older, $60 \%(p=.008)$ agreed or agreed fully. Similarly, those who had worked a shorter time in emergency services, were more interested in professional development. In the follow-up study, all of those who had under 3 years' experience of emergency care, but $88 \%$ of those with over 8 years' experience $(p=.010)$ expressed their interest in continuous professional development. Compared to the first survey, a greater share of the care providers made plans to seek further education in the near future. The rates were $61 \%$ and $72 \%$ respectively.

\subsubsection{Support and cooperation}

The majority of the respondents in both studies $(72 \%$ and $67 \%$ ) reported that they had received sufficient support from their colleagues, although the rate decreased to some extent from the first to the second study. Similar results were obtained in regard to the perceived support from the superior or employer. Before the intervention, nearly one third of the respondents felt that they had received sufficient support. In the follow-up study the rate was just $18 \%$. The older respondents in this study had more commonly the experience of being supported by their superiors or by the employer. In under 25 -year-olds, $29 \%$ reported perceived support from the superior or employer, whereas in 45-year-old or older respondents, the result was $47 \%(p=.028)$. In respondents who had worked over 8 years in emergency care, $26 \%$ reported having received support from their superiors/employer, while in those who had under 3 years' experience of working in emergency care, $16 \%$ agreed or agreed fully with this statement $(p=.007)$. In contrast to these results, there was an increase from the first (40\%) to the second (52\%) survey as regards the reported help and advice from the emergency doctor on duty.

Work in a multiprofessional environment was found less challenging after the intervention; the share of those who found the multiprofessional work community challenging decreased from nearly $40 \%$ to $23 \%$ of the respondents. A greater proportion of the respondents (86\%) also agreed with the statement that the cooperation with the dispatch centre was smooth, compared to the first survey (79\%). Cooperation with the regional hospitals, on the other hand, was rated slightly lower in the follow-up study. In the first survey, $43 \%$ of the care providers found the cooperation with the regional hospital smooth, whereas in the second survey, $39 \%$ of the respondents agreed or agreed fully. The older respondents seemed more satisfied with the cooperation; $25 \%$ of the under 25 -year-olds found that the cooperation was smooth, while in the age group 45 or older, the proportion of those who agreed was $60 \%(p=.026)$. Similarly, 53\% of those who had worked over 10 years in the health service found the cooperation smooth, whereas only $30 \%$ of those with 4 or less years in the health service felt the same way $(p=.049)$.

\subsection{Clinical skills}

As shown in Table 3, respondents rated their clinical skills slightly lower in the follow-up study than in the first survey, although a majority in both surveys found that they had good clinical skills. In the first survey, the majority of the respondents found that they had the following excellent individual skills: fluid care $(77.5 \%)$, care of lifeless patients (56.5\%), cardiopulmonary resuscitation (54.9\%) and circulation maintenance $(53.5 \%)$. In the follow-up study, respondents rated theirs skills as excellent as follows: fluid care $(65.1 \%)$, pain control (46.5\%), ECG performing and interpretation (44.2\%), circulation maintenance $(43.0 \%)$, care of lifeless patients $(40.7 \%)$, wound care $(39.5 \%)$ and cardiopulmonary resuscitation (38.4\%). Intubation skills were rated as completely or nearly lacking by part of the respondents in both the first $(17.6 \%)$ and the second survey $(38.4 \%)$.

Pain control skills were generally rated as good, but there was a difference between nurses and other professional groups. In the first survey, $62.0 \%$ of the nurses reported excellent pain control skills, whereas in the other groups, $32.0 \%$ $(p=.003)$ found that their skills were excellent. In the followup study, the rates were approximately $50.0 \%$ for nurses and $38.5 \%(p=.020)$ for the other professional groups.

None of the respondents rated their wound care skills as nearly or completely lacking. A difference was discovered between women and men in the follow-up study, where $51 \%$ of the women but only $21 \%$ of the men $(p=.019)$ assessed their wound care skills as excellent. Another difference emerged in respondents' perceived medication administration skills. The younger respondents in both surveys rated their skills slightly lower than the older age groups. In the first survey, $17 \%$ of the under 25 -year-olds assessed their 
medication administration skills as excellent, whereas in the older respondents, the rate was $50 \%(p=.020)$. In the follow-up study, one fourth of the under 25-year-olds and approximately half of the respondents in the older age groups rated their skills as excellent. A similar difference between age groups was discerned in both surveys as regards the care of unconscious patients. In the first survey, $35.0 \%$ of the under 25 -year-olds but $62.5 \%$ of the over 45 -year-olds ( $p=.007)$ found their skills excellent. After the intervention, the rates were $25.0 \%$ for the under 25 -year-olds and $67.0 \%$ $(p=.011)$ for the over 45-year-olds. As regards airway maintenance, all respondents in the follow-up study reported that their skills were at least average level. It was found in addition that nearly $40 \%$ of permanent staff but $21 \%$ of temporary staff rated their airway maintenance skills as excellent. In the first survey, the rates were $48 \%$ for permanent and $40 \%$ ( $p=$ $.000)$ for temporary staff. The results were similar when the length of work experience was examined; respondents who had worked longer in their current position had better clinical skills in airway maintenance. In those who had 4 or more years' experience, $50 \%$ felt that their skills were excellent. In care providers with 2 years or less work experience, only $4 \%$ $(p=.002)$ rated their airway maintenance skills as excellent.

Table 3. Emergency care providers' self-rated clinical skills

\begin{tabular}{|c|c|c|c|c|c|c|c|c|}
\hline \multirow[t]{2}{*}{ Clinical skills } & \multicolumn{2}{|c|}{$\begin{array}{l}\text { Survey } \\
\text { (Mean) }\end{array}$} & \multicolumn{2}{|c|}{$\begin{array}{c}\text { Survey } \\
\text { (Median) }\end{array}$} & \multicolumn{2}{|c|}{$\begin{array}{l}\text { Survey } \\
\text { (Range) }\end{array}$} & \multicolumn{2}{|c|}{$\begin{array}{c}\text { Survey } \\
(S D)\end{array}$} \\
\hline & $\mathbf{I}$ & II & I & II & I & II & $\mathbf{I}$ & II \\
\hline - Pain control $(\mathrm{N}=142, \mathrm{~N}=86)$ & 4.46 & 4.41 & 4.50 & 4.00 & $2-5$ & $2-5$ & 0.603 & 0.621 \\
\hline - Wound care $(\mathrm{N}=142, \mathrm{~N}=86)$ & 4.31 & 4.27 & 4.00 & 4.00 & $2-5$ & $2-5$ & 0.686 & 0.710 \\
\hline - Medication administration skills $(\mathrm{N}=142, \mathrm{~N}=86)$ & 4.42 & 4.27 & 4.00 & 4.00 & $2-5$ & $2-5$ & 0.611 & 0.583 \\
\hline - Care of unconscious patients $(\mathrm{N}=142, \mathrm{~N}=86)$ & 4.48 & 4.27 & 5.00 & 4.00 & $3-5$ & $3-5$ & 0.568 & 0.658 \\
\hline - Airway maintenance $(\mathrm{N}=142, \mathrm{~N}=86)$ & 4.40 & 4.26 & 5.00 & 4.00 & $2-5$ & $3-5$ & 0.608 & 0.617 \\
\hline - Circulation maintenance $(\mathrm{N}=142, \mathrm{~N}=86)$ & 4.52 & 4.36 & 5.00 & 4.00 & $3-5$ & $3-5$ & 0.529 & 0.612 \\
\hline - Intubation $(\mathrm{N}=142, \mathrm{~N}=86)$ & 3.02 & 2.26 & 3.00 & 2.00 & $1-5$ & $1-5$ & 1.313 & 1.210 \\
\hline - Cardiopulmonary resuscitation $(\mathrm{N}=142, \mathrm{~N}=86)$ & 4.51 & 4.31 & 5.00 & 4.00 & $3-5$ & $3-5$ & 0.580 & 0.599 \\
\hline - ECG performing and interpretation $(\mathrm{N}=142, \mathrm{~N}=86)$ & 4.48 & 4.38 & 5.00 & 4.00 & $3-5$ & $2-5$ & 0.555 & 0.617 \\
\hline - Fluid care $(\mathrm{N}=142, \mathrm{~N}=86)$ & 4.77 & 4.64 & 5.00 & 5.00 & $3-5$ & $3-5$ & 0.440 & 0.507 \\
\hline - Care of trauma patients $(\mathrm{N}=142, \mathrm{~N}=86)$ & 4.37 & 4.06 & 4.00 & 4.00 & $3-5$ & $2-5$ & 0.589 & 0.620 \\
\hline - Burn care $(\mathrm{N}=142, \mathrm{~N}=86)$ & 4.01 & 3.86 & 4.00 & 4.00 & $2-5$ & $2-5$ & 0.679 & 0.799 \\
\hline - Care of child patient $(\mathrm{N}=142, \mathrm{~N}=86)$ & 3.80 & 3.55 & 4.00 & 4.00 & $2-5$ & $1-5$ & 0.690 & 0.863 \\
\hline - Care of lifeless patients $(\mathrm{N}=142, \mathrm{~N}=86)$ & 4.51 & 4.30 & 5.00 & 4.00 & $3-5$ & $2-5$ & 0.592 & 0.687 \\
\hline - Care of gynecological patients $(\mathrm{N}=142, \mathrm{~N}=86)$ & 3.73 & 3.58 & 4.00 & 4.00 & $1-5$ & $1-5$ & 0.816 & 0.913 \\
\hline - Care of pregnant patients $(\mathrm{N}=142, \mathrm{~N}=86)$ & 3.89 & 3.59 & 4.00 & 4.00 & $2-5$ & $1-5$ & 0.782 & 0.937 \\
\hline
\end{tabular}

As mentioned above, the lowest rates were recorded for intubation. In the first survey, $30 \%$ of the under 25 -yearold respondents admitted that their skills were nearly or completely lacking. All care providers in the age group $>45$ years, however, possessed a minimum of average skills $(p<.000)$. In the follow-up study, the majority $(62.5 \%)$ of the under 25-year-olds reported that their clinical intubation skills were nearly or completely lacking. The older age groups found their intubation skills lacking much less commonly. The rates were $13 \%$ for over 45 -year-olds and $19 \%$ for 35-44-year-olds.

In regard to the care of lifeless patients, permanent staff rated their clinical skills higher than temporary staff. In permanent staff, $45 \%$ and in temporary staff, $26 \%(p=.036)$ of the respondents reported that their skills were excellent. All permanent staff members found that their skills were at least average level, whereas $10 \%$ of the temporary workers assessed their skills as quite lacking. In both surveys, respondents who had worked longest in their current position and in the health service, found their skills better than respondents with less work experience. In the follow-up study, excellent skills were reported by $53 \%$ of those who had worked over 4 years in their current position, but only by $21 \%$ of those who had 2 years or less experience of their current work $(p=.017)$. Similarly, $51 \%$ of the care providers with over 10 years' experience in the health service, but just $25 \%$ of the staff members with 4 years or less experience $(p=.023)$ said that their skills in caring for lifeless patients were excellent.

Respondents rated their skills in the care of gynecological patients lower in the second survey compared to the first survey. Excellent skills were reported by $21 \%$ of women and $4 \%$ of men $(p=.017)$ in the first survey and by $15 \%$ 
of women and $6 \%$ of men $(p=.030)$ in the second survey. Again, the follow-up study showed that respondents with a longer work history in the health service rated their skills higher. Of those with over 10 years of experience, nearly $20 \%$ said that their skills were excellent, while only $5 \%$ of the respondents with 4 years or less experience in the health service rated their skills as excellent $(p=.023)$. The followup study further revealed that respondents with more work experience in the health service found their skills slightly better in the care of pregnant patients: of those with 4 years of less experience, $15 \%$ and of those with over 10 years of experience, $18 \%$ found their skills excellent $(p=.018)$. In the first survey, $8 \%$ of those with under 3 years of experience in the health service and $23 \%$ of those with over 8 years' experience $(p=.031)$ rated their clinical skills in the care of pregnant patients as excellent.

\section{Discussion}

This research concentrates on a follow-up study conducted after a one-day educational intervention. The results show that, compared to the initial survey, emergency care providers' assessment of their work, its challenges and their clinical skills remained the same or deteriorated to some extent. ${ }^{[9,12]}$ The same questionnaire was sent to the same target group, to the out-of-hospital emergency staff of a hospital district, but the respondents were slightly older and the share of nurses was significantly higher in the follow-up study. It would not seem, however, that the changes in the age and professional structure could explain the differences discerned between the survey results. The results were mostly in the same direction and the differences were small. The decreased number of respondents in the follow-up study might be due to the fact that the latter survey was not conducted immediately, but approximately 6 months after the educational intervention. ${ }^{[22]}$

According to research evidence, emergency medical services have undergone major changes over the past decades, so that besides extensive clinical skills, wide-ranging competence is required from emergency care providers in encountering acutely ill patients and their family members and in managing the overall emergency incident. ${ }^{[23]}$ The role of clinical decision-making and treatment has been increasing as part of the emergency care providers' job description. ${ }^{[24]}$ Earlier, patients were more commonly transported to hospital for further care, while nowadays they are often treated on scene. ${ }^{[23,25]}$ Among other things, emergency care providers are expected to be able to assess and prioritize patients, provide emergency treatment, determine the patient's health status and assume an expert role in the management of emergency incidents. ${ }^{[26]}$ The care providers participating in this research rated their competence and individual clinical skills as good. Over two thirds of the respondents found that they possessed sufficient capability for working independently and implementing care quickly in changing circumstances. In an earlier study, conducted at an emergency department in Finland, staff reported that they experienced fear, caused by the risk of errors and by having to work in a hurry. ${ }^{[27]}$ One third of the respondents in this study felt that their work was dominated by constant rush, and almost two thirds agreed that their work constantly required new capacities from them.

The respondents in this study found that their work was interesting and involved sufficient challenges. Despite this, after the educational intervention half of the respondents found the work mentally taxing and over $40 \%$ found it physically strenuous, which was a slightly poorer result compared to the first survey. Earlier studies confirm that emergency care providers' work involves factors that can significantly burden them physically ${ }^{[28-30]}$ and mentally. ${ }^{[29]}$ Care providers are, for example, constantly exposed to physical demands, such as lifting and carrying, and moving stretchers. ${ }^{[28]}$

Respondents' self-rated clinical skills seem to have deteriorated to some extent after the educational intervention. Intubation skills, especially, were rated lower in the latter survey. The result can be partly explained by the fact that intubation is not a very common procedure and it is not regularly performed. ${ }^{[31]}$ In Finland, performing and assisting with intubation is taught to all nursing students using simulation and practical lessons, but not to practical nurse students. Nursing students gain a Bachelor's degree in a university of applied sciences, whereas practical nurse students study for a vocational qualification in an upper secondary level institution. Both groups of students, however, learn already during their basic education how to secure the patient's airway using an oral airway, I-gel, a larynx mask and a larynx tube. It is possible that the educational intervention made the respondents better aware of their shortcomings and of the need to develop their skills. Multi-professional simulation education has been suggested as a tool for promoting skills required for the less common procedures. ${ }^{[18]}$

After the one-day educational intervention offered to the whole emergency care staff, the majority of the participants expressed their willingness to develop their professional competence further. The results of this research show that their interest in updating and further education had increased. The results also indicate that updating and further education should be developed further to support emergency care providers' professional competence and development.

\section{Conclusions}

The results of this study show that the educational intervention had little effect on the emergency care providers' 
perception of their work, its challenges and their clinical skills.

Compared to the first survey, respondents partly assessed their clinical skills as poorer and the work as physically and mentally more taxing. The results indicate that the educational intervention should be reassessed and improved. Multiprofessional simulation education, especially, should

\section{REFERENCES}

[1] Squires JP, Mason S. Developing alternative ambulance response schemes: analysis of attitudes, barriers, and change. Emerg Med J. 2004; 21: 724-7. PMid: 15496710. https ://doi .org/10.1136/ emj. 2004.016923

[2] Evans R, McGovern R, Birch J, et al. Which extended paramedic skills are making impact in emergency care and can related to the UK paramedic system? A systematic review of the literature. Emerg Med J. 2013. Available from: http ://emj . bmj . com/content/early/ 2013/04/09/emermed-2012-202129. short

[3] Bigham BL, Kennedy SM, Drennan I, et al. Expanding paramedic scope of practice in the community: A systematic review of the literature. Prehosp Emerg Care. 2013; 17: 361-72. PMid: 23734989. https://doi.org/10.3109/10903127.2013.792890

[4] Ebben RHA, Vloet LCM, Speijers RF, et al. A patient-safety and professional perspective on non-conveyance in ambulance care: a systematic review. Scand J Trauma Resusc Emerg Med. 2017; 25(71): 1-25. https : //doi .org/10.1186/s13049-017-0409-6

[5] Mason S, Knowles E, Freeman J, et al. Safety of paramedics with extended skills. Acad Emerg Med. 2008; 15(7): 607-12. PMid: 18691211. https://doi.org/10.1111/j.1553-2712.2008.0 $0156 . \mathrm{x}$

[6] Lerner EB, Billittier AJ, Lance DR, et al. Can paramedics safely treat and discharge hypoglycemic patients in the field? Am J Emerg Med. 2003; 21: 115-20. PMid: 12671811. https ://doi.org/10.1053/ ajem. 2003. 50014

[7] Snooks HA, Dale J, Hartley-Sharpe C, et al. On-scene alternatives for emergency ambulance crews attending patients who do not need to travel to the accident and emergency department: a review of the literature. Emerg Med J. 2004 Mar; 21(2): 212-5. PMid: 14988356. https://doi.org/10.1136/emj.2003.005199

[8] Simpson PM, Bendall JC, Toson B, et al. Predictors of nontransport of older fallers who receive ambulance care. Prehosp Emerg Care. 2014; 18(3). https://doi.org/10.3109/10903127.2013.864355

[9] Mikkola R, Paavilainen E, Salminen-Tuomaala M, et al. Out-ofhospital emergency care providers' work and challenges in a changing care environment. Scand J Caring Sci. Early view article 2017. Available from: http://onlinelibrary.wiley.com/doi/10.1 111 /scs. 12456/full

[10] Paavilainen E, Mikkola R, Salminen-Tuomaala M, et al. Counseling patients and family members in out-of-hospital emergency situations: a survey for emergency staff. BMC Nurs. 2017; 16: 11. PMid: 28250716. https://doi.org/10.1186/s12912-017-0205-7

[11] Johnson M, O'Hara R, Hirst E, et al. Multiple triangulation and collaborative research using qualitative methods to explore decision making in pre-hospital emergency care. BMC Med Res Methodol. 2017; 17: 1-11. PMid: 28118817. https://doi.org/10.1186/ s12874-017-0290-z be developed. Participants expressed interest in further education to enhance their professional skills. In general, they found that their professional competence was good and that they had sufficient capabilities for implementing emergency care in changing circumstances.

\section{CONFLiCTS OF INTEREST Disclosure}

The authors declare they have no conflicts of interest.
[12] Salminen-Tuomaala M, Leikkola P, Mikkola R, et al. Workers' clinical skills at out-of-hospital emergency care. Emerg Med. 2015. Available from: https://www.omicsgroup.org/journals/wo rkers-clinical-skills-at-outofhospital-emergency-c are-2165-7548-1000291.php?aid=64013

[13] Kleinpell RM, Hravnak M, Werner KE, et al. Skills taught in acute care NP programs: a national survey. Nurse Pract. 2006; 31: 11-3. https : //doi.org/10.1097/00006205-200602000-00003

[14] Jouriles N, Burdick W, Hobgood C. Clinical assessment in emergency medicine. Acad Emerg Med. 2002; 9(11): 1289-94. PMid: 12414483 https://doi.org/10.1111/j.1553-2712.2002.tb01589.x

[15] Campbell D, Shepherd I, McGrail M, et al. Procedural skills practice and training needs of doctors, nurses, midwives and paramedics in rural Victoria. Adv Med Educ Pract. 2015; 6: 183-94. PMid: 25834473. https://doi.org/10.2147/AMEP.S77779

[16] Moore J, Prentice D, Salfi J. A mixed-methods pilot study of the factors that influence collaboration among registered nurses and registered practical nurses in acute care. Clin Nurs Stud. 2017; 5(4): 1-11. https://doi.org/10.5430/cns.v5n4p1

[17] Kalisch JB, Lee H. The impact of teamwork on missed nursing care. Nurs Outlook. 2010; 58: 233-41. PMid: 20934078. https : //doi.org/10.1016/j.outlook.2010.06.004

[18] Salminen-Tuomaala M, Jaskari P, Perälä S, et al. Nursing and medical staff's experiences of simulation education. Clin Nurs Stud. 2017; 5(4): 1-9. https : //doi .org/10.5430/cns . v5n4p73

[19] Salminen-Tuomaala M, Leikkola P, Paavilainen E. Patient and staff safety incidents and near misses in out-of-hospital emergency care. Emerg Med. 2014; 4: 5. https ://doi .org/10.4172/2165-754 8.1000219

[20] Plichta SB, Garzon LS. Statistics for nursing and allied health Philadelphia: Wolters Kluwer Health/Lippincott Williams \& Wilkins; 2009.

[21] Fouka G, Mantzorou M. What are the major ethical issues in conducting research? Is there a conflict between the research ethics and the nature of nursing? Health Sci J. 2011; 5(1): 3-14.

[22] Deutskens E, Ruyter KD, Wetzels M, et al. Response rate and response quality of internet-based surveys: An experimental study. Marketing letters. 2004; 15(1): 21-36. https ://doi.org/10.1023/B : MARK. 0000021968.86465 .00

[23] Cooper S, Grant J. New and emerging roles on out of hospital emergency care: a review of the international literature. Int Emerg Nurs. 2009; 17(2): 90-8. PMid: 19341994. https://doi.org/10.101 6/j.ienj.2008.11.004

[24] Joyce CM, Wainer J, Peterman L, et al. Trends in the paramedic workforce: a profession in transition. Aust Health Rev. 2009; 33(4): 53340. PMid: 20166901. https://doi.org/10.1071/AH090533

[25] Leikkola P, Mikkola R, Salminen-Tuomaala M, et al. Nonconveyance of patients: challenges to decision-making in emergency 
care. Clin Nurs Stud. 2016; 4(4): 31-9. https : //doi .org/10.543 $0 /$ cns.v4n4p31

[26] Clements R, Mackenzie R. Competence in prehospital care: evolving concepts. Emerg Med J. 2005; 22: 516-9. PMid: 15983094. https://doi.org/10.1136/emj.2005.026237

[27] Mikkola R, Huhtala H, Paavilainen E. Work-related fear and the threats of fear among emergency department nursing staff and physicians in Finland. J Clin Nurs. 2017b; 26(19-20): 2953-63. PMid: 27805740. https://doi.org/10.1111/jocn. 13633

[28] Coffey B, MacPhee R, Socha D, et al. A physical demands description of paramedic work in Canada. Int J Ind Ergon. 2016; 53: 355-62. https://doi.org/10.1016/j.ergon.2016.04.005
[29] Adriaenssens J, De Gucht V, Van Der Doef M, et al. Exploring the burden of emergency care: predictors of stress-health outcomes in emergency nurses. JAN. 2011; 67(6): 1317-28. PMid: 21371083. https://doi.org/10.1111/j.1365-2648.2010.05599.x

[30] Sofianopoulos S, Williams B, Archer F. Paramedics and the effects on shift work sleep: a literature review. BMJ. 2010. Available from: http://emj.bmj.com/content/early/2010/10/ $17 / \mathrm{emj} .2010 .094342$

[31] Deakin CD, King P, Thompson F. Prehospital advanced airway management by ambulance technicians and paramedics: is clinical practice sufficient to maintain skills? Emerg Med J. 2009; 26: 88891. PMid: 19934141. https://doi.org/10.1136/emj . 2008.0 64642 